\title{
Perceptions and Prospective Analysis of Artificial Intelligence and its impact on Human Resources in the Indonesian Industry 4.0
}

\author{
Btari Mariska Purwaamijaya ${ }^{1}$, Andrian Wijaya ${ }^{2}$, Shinta Berliana Shadani ${ }^{3}$ \\ \{btarimariska@upi.edu ${ }^{1}$, andrianwijaya@upi.edu ${ }^{2}$, shintabshadani@upi.edu $^{3}$ \} \\ Digital Business Study Program, Tasikmalaya Campus, Universitas Pendidikan Indonesia, Jl. Dadaha No. 18, \\ Tasikmalaya ${ }^{123}$
}

\begin{abstract}
In the current global era of the Industry 4.0, competent and highly competitive human resources are an absolute requirement for increasingly fierce global competition, to deal with this, the Indonesian government implemented policies to face the Indonesian Industry 4.0. One of which is done by the Ministry of Research and Technology's, for four years, around 100 new study programs have been opened in order to produce human resources who are ready to face challenges in the Indonesian Industry 4.0. In the current global era of the Industry 4.0, automation and robotics provide the muscle, AR / VR, cameras and other sensors provide the senses, data and connectivity are its central nervous system. But the real brains behind it is Artificial Intelligence (AI). AI, is a science in the field of computer science that studies the manufacturing of computer systems with the ability to have intelligence like humans. People who have the skill of AI are highly targeted today. The demand for artificial intelligence capabilities in the focus of the field of machine learning has risen sharply in the UK. Research is needed with a comprehensive qualitative approach, and exploration of needs to be anticipated by universities to become a center of excellence and contribute to the real world by producing human resources to be able to work and win competitions in the global business industry, both as practitioners and academics. The results of the study are useful for improving and aiming at evaluating the strategy that has been implemented previously based on the results of research related to perception and prospective analysis of artificial intelligence to produce the human resources needed in Indonesian Industry 4.0.
\end{abstract}

Keywords: Artificial Intelligence, Human resources, Industrial Revolution, Industry 4.0.

\section{$1 \quad$ Introduction}

The industrial revolution is a change in the economic sector and production in the form of efficiency aspects that affect other sectors. This century, the era of the Industrial Revolution 4.0 is ongoing with the rapid development of technology to digitize aspects of human life and connect it to the Internet of Things (IoT) and its 
supporting technologies serving as backbones for Cyber-Physical Systems (CPS) and smart machines are used as promoters to optimize production chains [1].

Artificial Intelligence (AI) is the driving force of the industrial revolution 4.0, which promises a lot of convenience for the government and industry sectors, especially related to Integration of AI in Human Resource [2]. In the midst of the massive industrial development 4.0, the government must move quickly in adopting this platform. Therefore, it is necessary to have the right knowledge and understanding for the government in facing the Industrial 4.0 era to combine research and business, one of which is in the Education sector [3]. The high demand for expertise in AI, makes several Universities as Centers of Excellence to produce graduates who can understand AI, by adding AI courses as an object of study in teaching and learning at the University, that will focus on developing deep learning and machine learning to solve cases against existing variables [4].

\section{Review Of Related Literature}

\subsection{Artificial Intelligence}

Artificial Intelligence (AI) is a computer system formed to find out, model human thought processes and design machines so that they can mimic human behavior. AI continues to grow along with technological developments and innovations found, so that it is expected to change the business world because of the efficiency of the AI process [5].

One of the Artificial Intelligence (AI) in the IT field, which is very familiar to use in Indonesia is chatbot. Chatbot is a computer program designed with artificial intelligence and natural language processing that makes chatbot a computer program that is intelligent and can answer questions given by humans. These chatbots can be used in small industries or businesses to automate customer service as user requests will be handled by chatbots thereby reducing labor requirements and human expenses [6].

AI in The Indonesian Industry 4.0

According to Asia Business Council research in 2017, on Artificial Intelligence in Asia: Preparedness and Resilience, reveals data that Indonesia is home to more than 100 million Internet users and 80 million smartphone users, which means a vast amount of potential data for companies that can crack the market for AI-enabled products and services. However, Indonesia is still working to 
fully enter the digital age, with the "1,000 Startup Digital National Movement Program". While Indonesia has not produced its own notable AI startups, Ematic Solutions as a Singapore-based digital marketing startup have focused on the Indonesian market. Ematic uses AI to capture data about visitors to a company's website. It then reflects the data on customers' interaction with the site to build a database of potential customers and to craft more effective digital ad campaigns. In addition, BLOCK 71 as is the third in a growing global network of incubation hubs managed by NUS, which include ventures in Singapore, San Francisco, and plans to expand to Suzhou in China will provide an ecosystem for disruptive technology startup companies [7].

AI for Human Resource Opportunities and Functions

A survey conducted by IBM of 6,000 executives in 2017 revealed that $66 \%$ of business owners (CEOs) trust cognitive computing and AI, capable of changing and directing new values significantly in the area of Resources Human (HR). Even 54\% of CEOs believe AI will fill and influence vital roles in HR. So far, Artificial Intelligence has played a role in several fields of work in order to help improve efficiency in various fields and now AI can be widely applied in various fields, such as health care, telecommunications, retail and education [8].

As explained in the paragraph above, the potential for AI embodies a new paradigm. For example, in healthcare, it affects health workers, researchers, and the public. Some particular AI technologies of high importance to healthcare have an important role to play in the healthcare offerings of the future. AI systems will not replace human clinicians on a large scale, but rather will augment their efforts to care for patients. Over time, human clinicians may move towards tasks and job designs that draw on unique human skills such as empathy, persuasion and bigpicture integration. Perhaps the only healthcare providers who will lose their jobs over time may be those who refuse to work alongside AI [9].

Based on the results of a paper from EY as a global leader in assurance, tax, transaction and advisory services, AI-based HR applications have strong potential to raise employee productivity and help HR professionals become knowledgeable consultants that boost employee performance. HR applications empowered by AI have an ability to analyze, predict, diagnose and become more powerful and capable resources. Determine what you would like to see and how it can fit within your corporate culture before adopting a solution. Employees will be affected by the AI function in multiple ways, so it is important to focus on employee needs and possible outcomes [10]. 


\section{AI Impacts on Education}

It can be understood that AI has reached all business sectors and even the education and HR sectors feel the impact of the presence of AI that will increasingly develop, to deal with this, the Indonesian government implemented policies to face the Indonesian Industry 4.0. One of which is done by the Ministry of Research and Technology's, for four years, around 100 new study programs have been opened in order to produce human resources who are ready to face challenges in the Indonesian Industry 4.0. The University as a Center of Excellence must be adaptive and develop continuously, as in the two major areas are curricula and enrollment. The strength of AI is its speed, accuracy, and consistency. However, on the other hand, AI is still weak in soft skills such as creativity, innovation, critical thinking, problem solving, socialization, leadership, empathy, collaboration, and communication. So training on the basics of science and mathematics can still run at the University, and at the same time the University must improve the soft skills of students. This anticipation has been carried out by several universities that offer AI and Machine Learning courses, which are not only limited to computer science students, but also now, business students as business managers and executives need to understand the capabilities, limitations, and implications of AI in the business world. The other impact of AI in higher education is enrollment. Liberal arts and humanities majors may become more popular as these areas are less susceptible to "AI-invasion." Areas such as accounting and financial analysis that may be hit hard by AI may see a drastic drop in enrollment. [11].

\subsection{Research Question}

The purpose of this study is to investigate the following research questions

- What perceptions does the public have about Artificial Intelligence and its impact on Human Resources in the Indonesian Industry 4.0?

- How are the prospects of government policy and the role of the business industry in Artificial Intelligence and its impact on Human Resources in Indonesia's Industry 4.0 ?

- What extent as AI been implemented in Universities in order to produce HR who are ready to compete in Indonesian Industry 4.0? 


\section{$3 \quad$ Research Methodology}

This research was conducted with a comprehensive qualitative approach, and exploration. Research based on secondary data from previous studies by exploring various articles, papers from company research and other literature. The study also adopted an interview method with the help of a structured questionnaire focused on students and faculty at the University, entrepreneurs and HR professionals working in companies. The study of Perceptions and Prospective Analysis of Artificial Intelligence and its impact on Human Resources in the Indonesian Industry 4.0 conducted a primary data collection from around 200 respondents in various educational backgrounds in Indonesia, both among students, academics and practitioners. Industry interviews were also conducted with five companies representing various business sectors in Indonesia in order to find out about Prospective Analysis of Artificial Intelligence and its impact on Human Resources in the Indonesian Industry 4.0.

\section{$4 \quad$ Result Analysis And Findings}

\subsection{Perceptions of Artificial Intelligence and its impact on Human Resources in the Indonesian Industry 4.0}

Perception is a response or finding a direct description of an or finding a direct description of a person's absorption in knowing some things through the five senses. In this sense it is clear, that perception is the impression of an image or response a person has after the person absorbs to know a few things (objects), through the five senses [12]. As for this study, perception indicators are presented as receiving or absorbing information, understanding, and evaluating.

Receiving information about Artificial Intelligence and its impact on Human Resources in the Indonesian Industry 4.0

From the results of questionnaire data distributed to 200 respondents in various educational backgrounds in Indonesia, 74\% of respondents knew about artificial intelligence and its impact on HR in Industry 4.0 in Indonesia. $72.72 \%$ of 165 students know about artificial intelligence, where $10.83 \%$ of them get information from newspaper or television news, $50.83 \%$ get it from social media such as news websites, Twitter, YouTube, line, Instagram, and Facebook. While 
only $20.83 \%$ get information from the University, $14.16 \%$, from seminars and $3,333 \%$ get it from other sources, such as international journals, articles and forums. $79.16 \%$ of 22 respondents who are entrepreneurs and employees know about artificial intelligence. Only $26.31 \%$ got information from the University, $21.05 \%$ got it from news sources in newspapers or television, $10.52 \%$ got it from seminars. $36.84 \%$ get it from social media. And unfortunately, only $5.26 \%$ get it from direct experience while working.

$69.23 \%$ of the 13 respondents were civil servants, teaching staff, and others, knowing about artificial intelligence and its impact on HR in Industry 4.0 in Indonesia. $11.11 \%$ of them get information from the University, $22.22 \%$ get it from news sources in newspapers or television, $22.22 \%$ get it from seminars, $22.22 \%$ get it from social media, and $22.22 \%$ get it from articles.

Understanding and Evaluating about Artificial Intelligence and its impact on Human Resources in the Indonesian Industry 4.0

Regarding the perceived importance of understanding IoT, big data, cloud computing and AI in Industry 4.0 in Indonesia in 200 respondents, $89.5 \%$ considered it important to understand it, 7\% considered it mediocre, and 3.5\% did not know that it was important. Regarding understanding of what is most influential on $\mathrm{HR}$ in Industry 4.0 in Indonesia, $15 \%$ answered renewable energy, $2.5 \%$ answered AR / VR, 28.5\% answered data and connectivity and 54\% answered AI. Respondents' assessment of the difficulty of studying and utilizing AI in Industry 4.0 in Indonesia, 49.5\% considered that difficult, $29.5 \%$ considered it normal, while $7.5 \%$ considered it not difficult, and $13.5 \%$ answered they did not know.

\subsection{The Prospects of Government Policy and The Role of The Business Industry in Artificial Intelligence and its impact on Human Resources in Indonesia's Industry 4.0}

Prospective analysis in terms of how the policies or implementation by the government are accepted by the public

From the final results of the questionnaire data with a total of 200 respondents, the information known can be seen in the following diagram. Regarding the effectiveness of the implementation of policies from the Ministry of Communication and Information Technology, $78 \%$ or it can be said that the majority of people are not aware of the policy and about sources of information related to policy implementation from the Ministry of Communication and Information Technology, it is known that social media is the largest source of information at $14 \%$. 

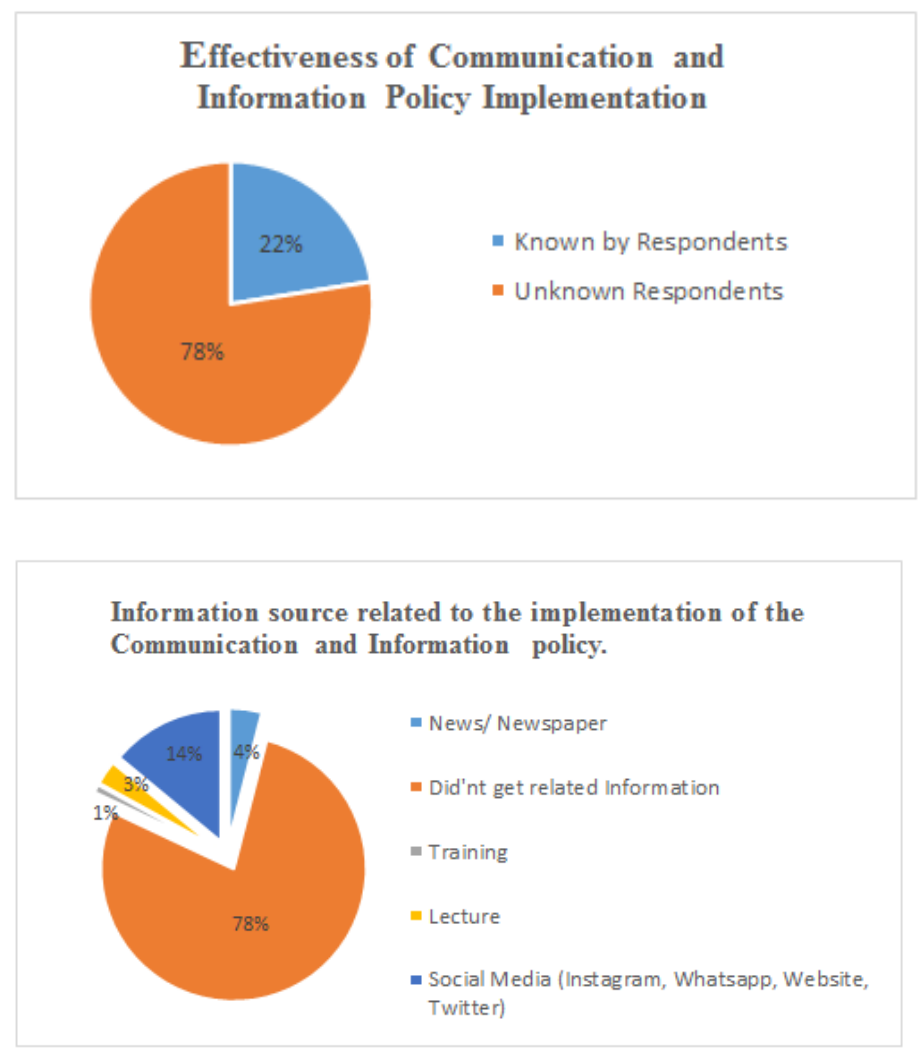

Based on the data we obtained, it is known that the new regulations related to the opening of relevant new study programs, the results are balanced. Based on the relevance of government programs to produce HR in Industry 4.0, the opening of new study programs is the most relevant government program, which is $51 \%$. 

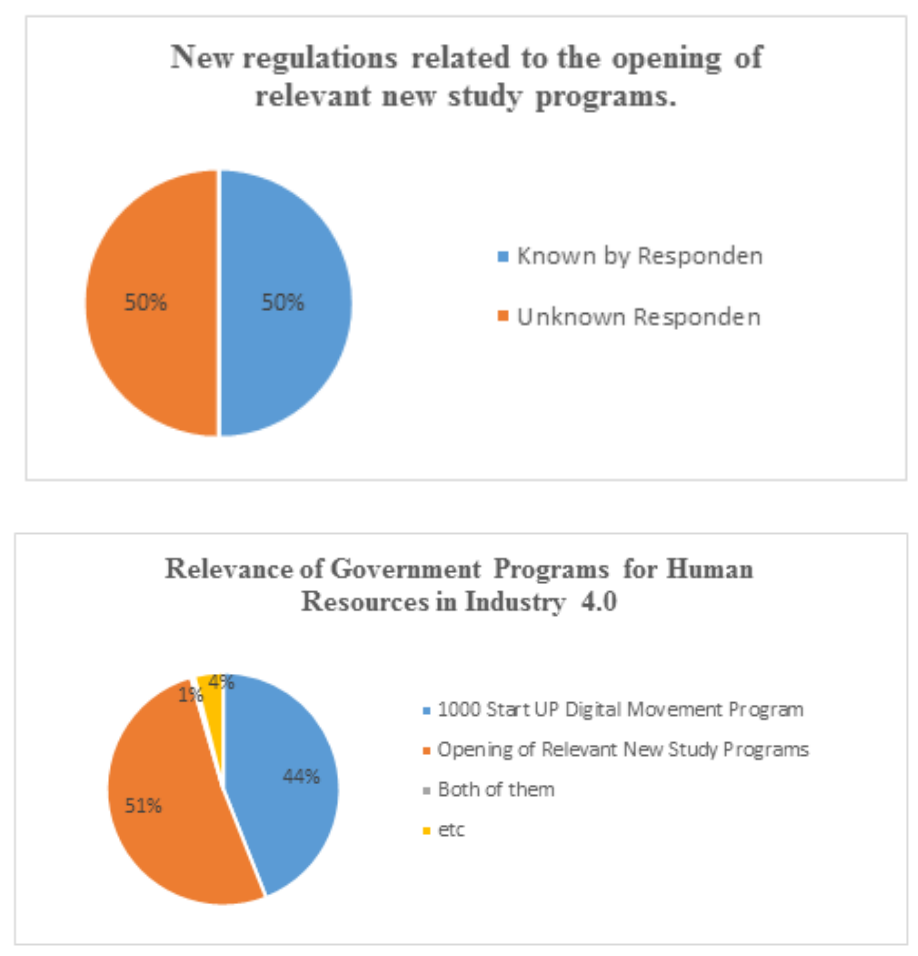

Based on the data we obtained, the response of respondents to the statement "The role of the government to produce human resources in industry 4.0 in Indonesia" states that the role of government is important at $90 \%$. Regarding the effectiveness of the implementation of government policies, $82 \%$ of respondents stated that government policies were not effective. Based on the data above, the lack of program socialization and the lack of adequate infrastructure $(60 \%)$ are mutually sustainable towards the lack of implementation of government policies to produce HR in Industry 4.0. 

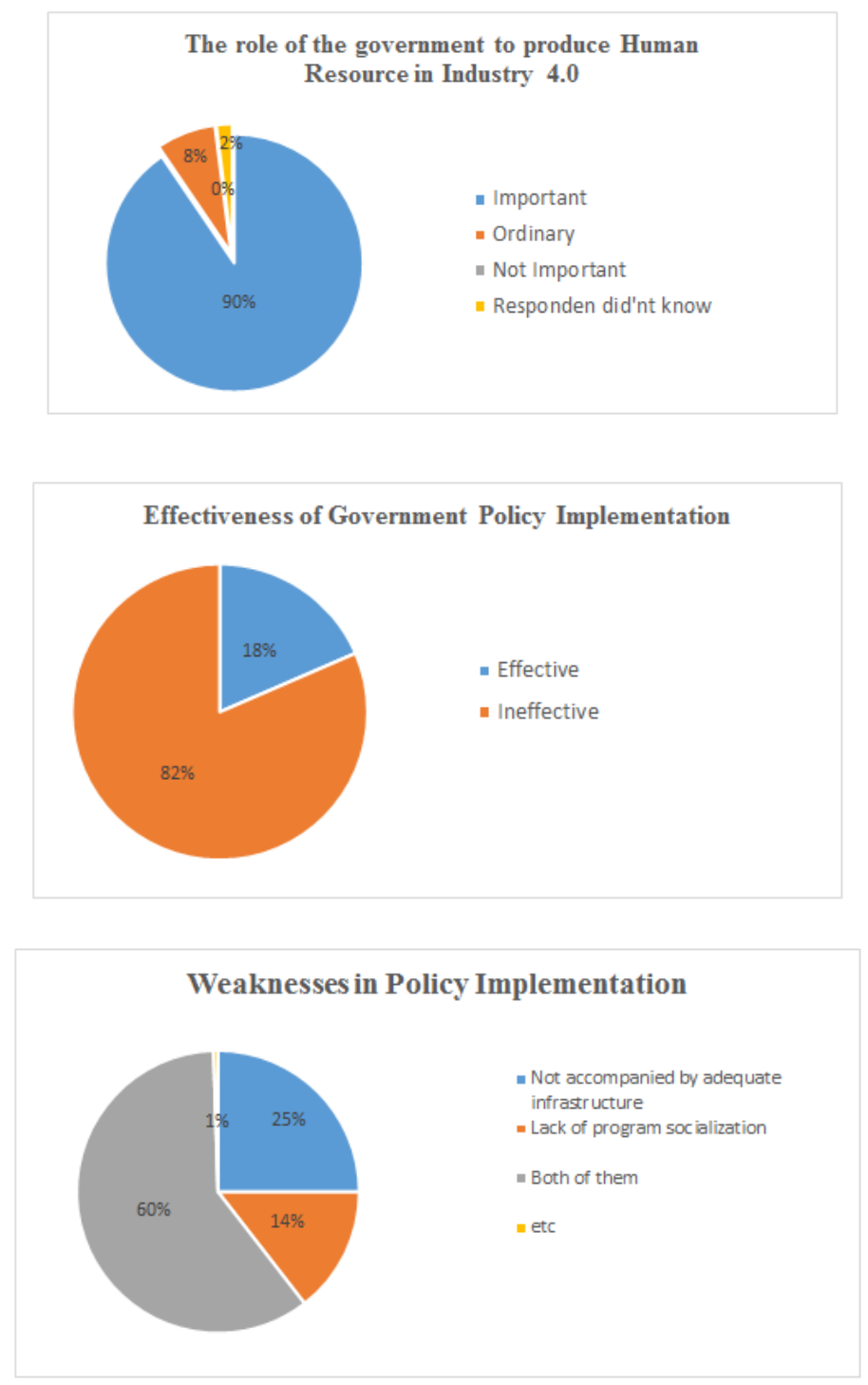

Prospective analysis of the results of industry interviews

In this study, industry interviews were conducted at five companies. PT. Centratama Telekomunikasi Indonesia Tbk, Permata Family Hospital Lippo Cikarang, CV. Putra Dirgantara Jaya, PK. Indah Jaya, and PT. Yuditama Mandiri, 
all five are private companies. One company has less than 10 workers, there is one company that has 10-20 workers, and three other companies have more than 20 workers.

Based on the results of a questionnaire about HR that has an understanding of AI, several companies have their own answers. $66.7 \%$ of companies agreed to apply AI to their company and $33.3 \%$ answered they did not agree to apply AI to their company.

PT. Centratama Telekomunikasi Indonesia Tbk and PT. Yuditama Mandiri said that HR who had an understanding of AI had the opportunity to work at the company with different percentages. The magnitude of the percentage of undergraduate graduates who understand AI, at PT. Centratama Telekomunikasi Indonesia Tbk, has a percentage to be recruited at the company of $<10 \%$, while PT. Yuditama Mandiri has a percentage of $10-25 \%$ to be recruited at the company. For the recruitment of new graduates with a bachelor's degree in the company PT. Centratama Telekomunikasi Indonesia Tbk, PK. Indah Jaya and PT. Yuditama Mandiri is conducted every more than two years and regarding salaries for HR who understand AI is not special, just standard, for the initial entry into PT. Centratama Telekomunikasi Indonesia Tbk will get a salary of $>6$ million rupiah. Meanwhile at PT. Yuditama Mandiri gets a salary of between 4 - 6 million rupiah. Meanwhile, Permata Family Hospital Lippo Cikarang, CV. Putra Dirgantara Jaya, and PK. Indah Jaya, does not need human resources who understand AI.

\subsection{The role of Universities to produce competent students in the Industrial Revolution 4.0 era}

Regarding the importance of the role of universities in producing human resources who are ready to compete in industry 4.0 in Indonesia, $73.5 \%$ of 200 respondents answered very important, $23.5 \%$ answered important, 3\% answered mediocre, and $0.5 \%$ answered unimportant. Regarding the application of curriculum and career guidance that has been carried out by the University to produce Human Resources (HR) who are ready to compete in Industry $4.0,16.5 \%$ of the 200 respondents answered that they have been very helpful, $60.5 \%$ answered quite helpful, 5\% answered unhelpful, and $18 \%$ want changes or adjustments to the curriculum that are in line with industry 4.0 .

Regarding what the university has to do in producing competent human resources in industry $4.0,16.5 \%$ of the 200 respondents proposed opening an

artificial intelligence study program, $60.5 \%$ considered that additional courses such 
as entrepreneurship, digital business and artificial intelligence were needed. 20\% suggest that universities need to hold work seminars needed by companies in industry 4.0 and 3\% consider what the University is doing is enough so there is no need to do anything.

Regarding the role of lecturers from practitioners to prepare students. $89.5 \%$ answered very important. While $10 \%$ answered that it was mediocre and $0.5 \%$ answered unnecessary. Regarding the knowledge of lecturers about IT especially on artificial intelligence to help students find work in the future, $86.5 \%$ answered that it was very necessary. $12.5 \%$ answered normal and $1 \%$ answered unnecessary for lecturers to understand this.

Regarding study programs that can be replaced with artificial intelligence, $18.5 \%$ answered could be replaced by artificial intelligence, $9.5 \%$ answered could not be replaced and $72 \%$ answered might be replaced by artificial intelligence. Regarding the infrastructure needed to support the 4.0 industry, 54\% consider that an IT / multimedia lab is needed. On the other hand $27 \%$ answered that business incubators were needed, $6 \%$ considered that a wifi corner, and $13 \%$ assumed that a digital library was needed to support Industry 4.0.

From the results of our brief interview with the respondents, that the respondents' expectations to the government or the University in the development of Business Industry sectors in relation to artificial intelligence and HR development to deal with Industry 4.0 is that there is visible progress in the application of artificial intelligence technology, the University must able to adapt to the development and implementation of artificial intelligence or automation, the implementation of an appropriate curriculum to be applied in industry 4.0 that artificial intelligence is made a matter of general knowledge, especially the learning process is supported by infrastructure that matches the specifications for learning, the government must be able to make policies that are expected to promote and carry out digitalization to SMEs or businesses by implementing artificial intelligence for support in industry 4.0.

\subsection{Implication Of The Study}

Even though there are many articles about AI and its effects on HR, there are still limited research-based articles in Indonesia. Therefore, there are limitations to academic research conducted to reveal how the relationship between AI, HR and its benefits in the Industrial Revolution 4.0. This study based on qualitative research contributes to the development of AI and HR. The findings from this study show 
how actually HR can be more competent with AI integrated and how to make it more effective and systematic. This study also highlights various needs in producing human resources in order to be able to integrate AI. These findings illustrate the reasons how AI should be integrated into the HR function by all companies and how collaboration between government and universities is needed.

\section{Conclusions}

The industrial revolution 4.0 has brought many developments, the era of automation has been applied in several sectors to streamline activities and artificial intelligence as a driving force in this Era that promises many conveniences in various fields. Based on the results of research, the Indonesian people have known artificial intelligence but only in general from various sources. However, they do not yet know how to implement artificial intelligence in various sectors. Indonesian people's awareness has existed that artificial intelligence is an important thing that must be understood in the era of industry 4.0, it's just that their assumptions about how difficult it is to study artificial intelligence has prevented understanding deeper about artificial intelligence itself.

Based on research that policies made by the government, one of which is by the Ministry of Information and Communication Technology is not well spread and can not be known by the wider community. In fact, the policy to facilitate the University in opening new study programs to meet the demand for HR in industry 4.0 in the future is also in the same challenge. The Indonesian people assume that the role of government must exist, but instead that role becomes less on target, because information is not distributed evenly to the Indonesian people themselves. On the other hand the results of research involving the industry were not ready to accept human resources who understand artificial intelligence and there is an assumption that character is more important to deal with industry 4.0 , because it is considered artificial intelligence cannot replace the value of human character.

HR is a crucial variable in Indonesia's changing movement to prepare industry 4.0. The competent agency for this is the Ministry of Education and Culture. Education is the beginning to produce competent human resources in facing and fulfilling everything needed in Industry 4.0. According to research results, Indonesians want changes in the curriculum at the university by adjusting demand to industry 4.0, such as adding additional courses and applying information technology 
primarily to artificial intelligence to help them professionally. They also realized the importance of lecturers from practitioners to increase knowledge about professional work. Infrastructure is needed by the University to produce competent human resources in industry 4.0, to help students express and form ideas more easily with supporting infrastructure.

\section{References}

[1] Liao, Y., Loures, E. R., Deschamps, F., Brezinski, G., \& Venâncio, A. 2017. The impact of the fourth industrial revolution: a cross-country/region comparison. Production, 28, e20180061. DOI: 10.1590/010365

[2] 13.20180061

[3] George, G., Thomas, M.R. 2019. Integration of Artificial Intelligence in Human Resource. In International Journal of Innovative Technology and Exploring Engineering (IJITEE). ISSN: 2278-3075, Volume-9 Issue2, December 2019, 5069-5073. DOI: 10.35940/ijitee.L3364.129219

[4] Palmieri, S., Amandolese, D. 2018. Industry 4.0: Universities and Companies Together to Combine Research and Business. In 12th International Technology, Education and Development Conference, March 2018. DOI: 10.21125/inted.2018.0492.

[5] Abdeldayem, M.M., Aldulaimi, S.H. 2020. Trends And Opportunities Of Artificial Intelligence In Human Resource Management: Aspirations For Public Sector In Bahrain. In International Journal of Scientific \& Technology Research Volume 9, Issue 01, January 2020, 3867-3871.

[6] Sannella, M. J. 1994. Shabbir, J., Anwer, T. 2015. Artificial Intelligence and its Role in Near Future. In Journal of Latex Class Files, Vol. 14, No. 8, AUGUST 2015, 1-11.

[7] Haristiani, N. 2019. Artificial Intelligence (AI) Chatbot as Language Learning Medium: An inquiry. In International Conference on Education, Science and Technology 2019, 1-6. DOI:10.1088/1742$6596 / 1387 / 1 / 012020$

[8] Pau, J., Baker, J., Houston, N. 2017. Artificial Intelligence in Asia: Preparedness and Resilience, 15-16.

[9] Thompson, V. 2017. IBM Study - C-Suite innovators say AI will make biggest impact on personalizing customer experience, accessed July 6, 2020, https:/www.ibm.com/blogs/watson/2017/09/ibm-study-csuite-innovators-say-ai-will-make-biggest-impact-on-customer-experience/

[10] Davenport, T., Kalakota, R. 2019. The potential for artificial intelligence in healthcare. In Future Healthcare Journal, 94-98. DOI: 10.7861/futurehosp.6-2-94.

[11] EY. The new age: artificial intelligence for human resource opportunities and functions, 1-11.

[12] Siau, K., Ma, Y. 2018. Artificial Intelligence Impacts on Higher Education. In Thirteenth Annual Midwest Association for Information Systems Conference (MWAIS 2018), At St. Louis, Missouri.

[13] Kowang, T.O., Long, C.S., Rasli, A., Fei, G. C. 2015. Perception versus Performance Indicators: A Study of Innovation Performance in a Research University. DOI: 10.5539/ass.v12n1p24, 1-29. 